\title{
O USO DE JOGOS PARA ENSINAR INGLÊS COMO SEGUNDA LÍNGUA
}

\section{REVISÃO DO ARTIGO}

DIAS, Adailton Di Lauro ${ }^{1}$

DIAS, Adailton Di Lauro. O uso de jogos para ensinar inglês como segunda língua. Revista Científica Multidisciplinar Núcleo do Conhecimento. Ano 04, Ed. 07, Vol. 03, pp. 69-76. julho de 2019. ISSN:2448-0959

\section{RESUMO}

Avaliando as práticas de ensino atuais e até mesmo observando aspectos historicamente metodológicos, os alunos hoje enfrentam uma dificuldade extrema para desenvolver as habilidades cognitivas e adquirir conhecimento no sistema educacional atual. Talvez isso não se deva à ineficácia dos métodos, mas à dinâmica das relações entre o aluno e o meio ambiente. Diferentes faixas etárias requerem abordagens diferentes, que mudaram para a condição de obsolescência; eles perdem sua eficácia significativamente, à medida que o tempo passa. Assim, os jogos em termos de idade e assuntos podem ser uma maneira eficiente de exibir conteúdo devido à sua universalidade. O presente artigo tem como objetivo explicar as razões pelas quais os jogos constituem uma ferramenta importante na educação e indicar algumas maneiras de aplicar essas ferramentas no processo de ensino e aprendizagem do Inglês como segunda língua.

Palavras-chave: Jogo, habilidade, linguagem, emoções, processo de aprendizagem.

\footnotetext{
${ }^{1}$ Mestrado em Educação Científica na Universidade Unigrendal. Especialista em Inglês pela FIJ-Integrated Colleges of Jacarepagua, Rio de Janeiro (2007). Formada em Literatura pela Universidade do Estado da Bahia, Brasil. Professor de Inglês e Português no IFRR-Brasil.
} 


\section{INTRODUÇÃO}

Considerando o progresso tecnológico em ritmo constante e, ainda mais, observando que as metodologias devem acompanhar essas mudanças com o objetivo de melhoria constante, este artigo busca relacionar o uso dos jogos à prática do ensino do inglês como segunda língua. $O$ estudo não se restringe a um modelo específico do jogo, mas a qualquer forma lúdica de simular a realidade. Assim, a análise detalha alguns tipos de jogos e seus aspectos históricos, observando a estreita relação entre eles, o contexto e o processo de aprendizagem. A proposta atual pode convergir para uma criação de práticas, que utilizam jogos para tornar 0 ato de aprendizagem agradável para os alunos; ele também pode ajudá-los a usar o conteúdo proposto de forma fluente e eficiente em suas vidas diárias.

A falta de situações reais que contribuem para a prática de nova língua pelos alunos constitui uma das maiores dificuldades para o processo de ensino de Inglês. No ambiente da sala de aula, diferentes atividades podem atender parte dessa lacuna se o professor desenvolver o interesse dos alunos na aprendizagem, concentrando-se nas aulas e atividades expositivas. Ao considerar as muitas possibilidades em um ambiente onde os alunos podem simular situações extracurriculares e entrar no contexto dessas situações, um resultado melhor pode ser obtido. As perspectivas de ordem conceitual neste estudo consideram a literatura indicada, mas principalmente, considera a experiência do autor na práxis pedagógica, principalmente no ensino de inglês como segunda língua. Portanto, a visão do autor e substituto de observação, neste estudo, a pesquisa de campo usual necessária.

Com base em pesquisas de jogos para crianças, jogos e outros conceitos e assuntos relacionados, existem diferentes formas de aplicação deste estudo na esfera pedagógica. Para Dantas (1998) "o termo lúdico refere-se ao ato de jogar (de forma livre e individual) e jogar (no que diz respeito a uma conduta social que envolve regras)." No entanto, a relação específica e dinâmica entre o método e os alunos torna necessário o aprofundamento e a direção dos jogos para cada disciplina. De acordo com a ANTUNES (2003), para tornar os jogos atestáveis para a prática de ensino eficaz é necessária análise e pesquisa, pois o resultado pode ser revertido se não 
houver compatibilidade entre eles e o objeto de aprendizagem. A literatura utilizada orienta parte da construção de conceitos sem definir a aplicabilidade dos jogos. Assim, o autor é quem sugere tal uso prático e sua possível convergência metodológica.

\section{ALGUMAS CONSIDERAÇÕES SOBRE OS PASSOS PARA A APRENDIZAGEM}

Um ponto importante a ser considerado é o contexto e as condições, que são aplicadas aos mecanismos de aprendizagem. No que diz respeito aos jogos, o público é muito heterogêneo, dada a variedade de jogos existentes e alcance ilimitado relacionado com as idades dos alunos. O jogo é uma atividade espontânea, realizada por uma ou mais pessoas e, de forma diferente da arte e do trabalho, pode ser considerada como um meio de estimulação física ou mental, às vezes ambos. A existência dos jogos remonta aos tempos pré-históricos e abrange todos os níveis de experiência, gêneros e idades. Entre as etapas de aprendizagem, é importante entender que os obstáculos à sobrevivência são a justificativa para os diferentes processos. Assim, esses processos ocorrem em uma escala de complexidade crescente. A criação de operações necessárias para superar esses impedimentos, passa por diferentes e bem definidas fases, desde a infância até a adolescência.

A primeira etapa começa no nascimento e geralmente dura até o início da aquisição da linguagem (até cerca de dezoito meses de idade). Durante este período, inicia-se a formação de habilidades motoras e percepção sensorial. A segunda etapa ocorre aproximadamente entre dois e quatro anos de idade e é definida pela formação de pensamento simbólico. $O$ uso de bonecas, carros e outros objetos de natureza simbólica que simulam a realidade, constituem parte dessa fase particular. Entre quatro e oito anos de idade, aparece o terceiro estágio, onde o pensamento intuitivo começa a ser formado e os objetos ao redor se tornam os pontos de referência.

Automaticamente, esta intuição leva ao quarto estágio, que é o estágio em que os seres humanos aprendem a organizar operações concretas para associar qualquer objeto referenciado ao seu significado. A quarta fase dura entre quatro a oito anos de idade. A última etapa é concluída durante a adolescência, onde a construção de 
operações mentais é suficiente para o pensamento analítico. Tomando essas medidas e suas distinções, é possível entender que a adequação dos jogos para diferentes faixas etárias pode atender a maioria de seus membros.

\section{USANDO OS JOGOS COMO UM SUPORTE PARA ENSINAR INGLÊS}

Para WITTGENSTEIN (2001), o conceito de "jogo" não pode ser restrito a uma única definição, mas como uma multiplicidade de configurações para estabelecer uma relação de semelhança familiar entre eles. A definição de multiplicidade de Wittgenstein encontra apoio também no CALLOIS (1957), que dá algumas características necessárias para que uma atividade seja definida como um jogo. As condições são que a atividade precisa ser divertida, limitada no tempo e no lugar, de resultado imprevisível e isso não é produtivo. Além disso, a atividade deve ter regras diferentes da vida cotidiana e deve ser fictícia, acompanhada pela consciência de uma realidade diferente. Os jogos devem, portanto, abordar o real para o imaginário e para a sala de aula, ou o espaço alternativo escolhido deve ser um ambiente adequado para essas práticas.

O uso da repetição nos níveis de linguagem, ao ensinar inglês, deve ocorrer como o processo de ensino da língua materna, mesmo para adultos iniciantes. Exceto para a gramática de aprendizagem, a técnica de aprender inglês com o dedo indicador apontando para imagens ou objetos é muito eficiente. $O$ professor deve realizar a apresentação da língua de forma clara e nos jogos, você deve evitar atividades que levam ao tédio ou distração. No início, tarefas como tradução e gramática têm muito pouco mérito real, uma vez que a linguagem escrita é secundária neste momento. $\mathrm{O}$ principal objetivo é vincular a linguagem ao contexto e ao ambiente real, abstrato ou fictício dos jogos.

A escolha dos jogos deve ser orientada pela aplicabilidade à faixa etária em questão, viabilidade técnica e condição de monitoramento pelo professor em todas as fases de atividade. Assim, os jogos educacionais do construtor ou do instrutor podem ser usados desde que encontram as exigências acima. De acordo com o propósito, 
qualquer tipo de jogo pode ser usado dependendo de várias condições, mas é importante capturar o interesse de toda a comunidade envolvida. A seguir estão alguns tipos de jogo definido que podem ser usados:

\subsection{JOGOS INTERATIVOS E DE INTERCÂMBIO}

Estes jogos são usados para se juntar ao membro de um grupo. Eles ajudam os participantes a memorizar informações específicas e promover um ambiente descontraído. Os jogadores se distraem liberando tensões e superaram problemas pessoais. Eles devem ser usados nas primeiras fases do desenvolvimento de um grupo, ao iniciar uma reunião, depois de uma pausa e cada vez que o grupo parece começar a ficar cansado, entediado ou não motivado.

Música e dança são recomendadas em jogos ativos para sintonizar o grupo na atividade proposta. A decisão ideal é usar jogos curtos com muita ação e um alto gasto de energia.

\subsection{JOGOS DE TOQUE E CONFIANÇA}

Estes jogos ajudam os participantes a assistir-se lidar com a confiança em suas vidas. De acordo com a organização cultural e o nível de abertura de pessoas, o grupo pode ir gradualmente a outros exercícios que envolvem o toque. Os jogos de toque e confiança devem ser usados com muito cuidado; o instrutor deve estar atento ao momento e às reações do grupo, bem como dos participantes, oferecendo-lhes recursos para lidar bem com fortes processos psicológicos internos.

\subsection{JOGOS DE CRIATIVIDADE E REFLEXÃO}

Estes são jogos que estimulam a expressão imaginária, intuição e criatividade. Nesses jogos, os participantes podem se notar e mostrar abertamente aos outros o que descobriram sobre si mesmos, sobre o assunto estudado e sobre o grupo. Os jogadores entram em contato com seu interior e dentro de outros jogadores, percebendo o que é mais relevante em todos os níveis. Este tipo de jogo deve ser 
usado quando os grupos estão completamente integrados, trabalhando juntos e usando todas as condições para ir profundamente para o assunto estudado até aquele momento.

\subsection{JOGOS DE GESTÃO}

Esses jogos concentram a atenção dos jogadores no planejamento, gerenciamento de recursos, simulação de situações e aprendizado de técnicas específicas. Este tipo de jogo deve ser usado depois que o grupo está bem integrado para que eles possam chegar ao objetivo proposto. Às vezes é comum aparecer algumas dificuldades em aprender o assunto assim que é muito importante que todo o ciclo de aprendizagem vivo está sendo trabalhado completamente.

\subsection{JOGOS DE ENCERRAMENTO}

Esses jogos ajudam as pessoas a ter a chance de definir sua posição relacionada a um assunto, ao grupo e a si mesmas, transferindo o que obtiveram durante o processo de aprendizagem para suas vidas cotidianas. Os jogos sintetizadores e finais são aqueles que ritualizam, avaliam e formalizam o que foi feito durante o trabalho. É realmente importante deixar claro, para cada participante, que um ciclo está sendo terminado e outro está começando.

\subsection{JOGOS DE HABILIDADE E ESTRATÉGIA}

Pode ser usado em qualquer etapa do processo ou situações. É importante destacar que o esporte está incluído em quase todas as modalidades explicadas acima, mas deve ser usado para envolver o grupo sobre o aspecto da aprendizagem, mas sem abandonar o aspecto competitivo, que é precisamente o que atrai o público de a maioria das faixas etárias. O jogo, realizado como uma atividade de prazer, constituise como uma ferramenta a ser estudada e aplicada ao ensino de Inglês, principalmente porque se sabe que nossos cérebros aprendem através de um processo de repetição, julgamento e velocidade (VILLA \& SANTANDER, 2003). O ensaio, ou experimentação, é a análise da situação. A repetição dá a prática que leva 
à velocidade, ou eficiência e eficácia. A capacidade de cada aluno apontará qual nível de jogo deve ser usado.

Compreender, portanto, as diferentes definições de jogos e a questão dos princípios de aprendizagem com os seres humanos, torna-se clara a condição de pleno uso deles nas práticas de ensino. $O$ interesse do estudante na aprendizagem fica ligado ao seu interesse no jogo proposto no momento. $\mathrm{O}$ ambiente criado pelo jogo, levando também em conta que as emoções que influenciam os seres humanos também promovem a assimilação, podem suprir a falta de situações reais. Assim, quanto maior a emoção causada nos jogos, maior a possibilidade de definir o conteúdo proposto.

Emoções positivas promovem mais aprendizagem (SISTO \& MARTINELLI, 2006), de modo que o sentimento de alegria supera a tristeza ou dor. O professor, por sua vez, começa a atuar como mediador entre o real e a imaginação representado pelo jogo e seu resultado. A sala de aula muda de um lugar de discurso pedagógico para um laboratório para compartilhar experiências, cheia de possibilidades.

\section{CONCLUSÃO}

Este estudo tentou fornecer uma alternativa ao processo de ensino de inglês como segunda língua, por meio de jogos, buscando agregar valores ao contexto educacional atual. Ensinar uma língua, fora de seu ambiente natural, é um processo que exija a habilidade e a faculdade criadora pelo profissional envolvido. Em seguida, a partir do momento de escolher os jogos para a análise dos resultados, o professor deve ter o cuidado de acompanhar os desenvolvimentos do reconhecimento dos alunos, a fim de não perder o objetivo real. $O$ foco é não só desenvolver estratégias, mas também fazê-las funcionar corretamente.

Certamente, o assunto não termina. O estudo constante e o compartilhamento de experiências continuam a ser de responsabilidade dos indivíduos envolvidos no processo de ensino e aprendizagem. O maior ou menor uso e disseminação do processo em que as práticas sugeridas são utilizadas determinará o sucesso delas. 
Considerando o espaço de educação como algo a ser melhorado e, de acordo com seu dinamismo, não pode manter os conceitos estáticos e obsoletos.

\section{REFERÊNCIAS}

ABERASTURY, A. A criança e seus jogos. Porto Alegre: Artes Médicas, 1992.

AFFONSO, R. M. Ludodiagnóstico. São Paulo: Plêiade, 1995.

AGUIAR, J. S. Jogos para o ensino de conceitos: leitura e escrita na pré-escola. Campinas: Papirus, 1998.

ANTUNES, C. Jogos para a estimulação das múltiplas inteligências. $12^{a}$ edição. Petrópolis, RJ: Vozes, 2003.

CALLOIS, Roger. Les Jeux et les hommes. Paris: Gallimard, 1957.

DANTAS, H. Brincar e Trabalhar. In: KISHIMOTO, T. M. (org). Brincar e suas teorias. São Paulo: Pioneira, 1998.

SISTO, F. F. \& MARTINELLI, S. de C. (orgs.) Afetividade e dificuldades de aprendizagem: uma abordagem psicoeducacional. São Paulo: Vetor, 2006.

VILA, Magda \& SANTANDER, Marli. Jogos cooperativos no processo de aprendizagem acelerada. São Paulo: Qualitymark, 2003

WITTGENSTEIN, Philosophical Investigations, Blackwell Publishing Ltd., MA: 2001.

Enviado: junho de 2019.

Aprovado: julho de 2019. 